\title{
Synthesis and electrical characterization of intrinsic and in situ doped Si nanowires using a novel precursor
}

\author{
Wolfgang Molnar ${ }^{1}$, Alois Lugstein ${ }^{* 1}$, Tomasz Wojcik², Peter Pongratz ${ }^{2}$, \\ Norbert Auner ${ }^{3,4}$, Christian Bauch ${ }^{3,4}$ and Emmerich Bertagnolli ${ }^{1}$
}

\section{Full Research Paper}

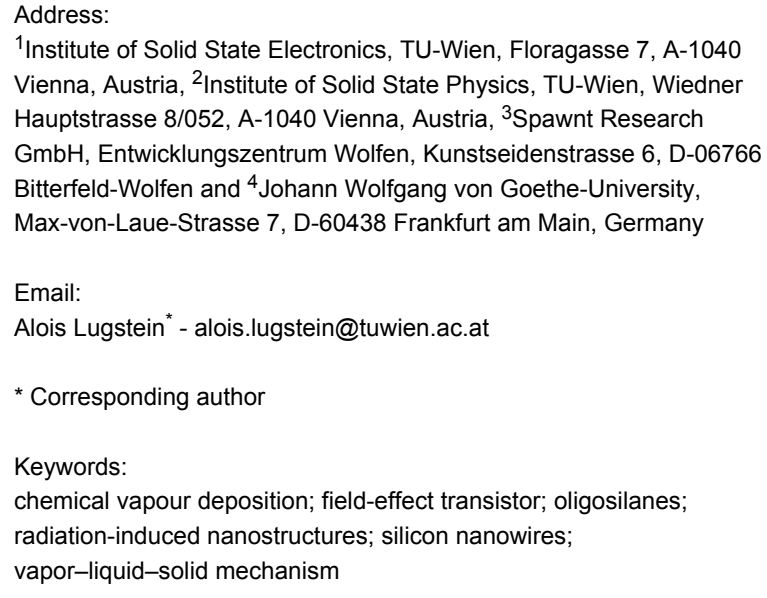

${ }^{1}$ Institute of Solid State Electronics, TU-Wien, Floragasse 7, A-1040 Vienna, Austria, ${ }^{2}$ Institute of Solid State Physics, TU-Wien, Wiedner Hauptstrasse 8/052, A-1040 Vienna, Austria, ${ }^{3}$ Spawnt Research $\mathrm{GmbH}$, Entwicklungszentrum Wolfen, Kunstseidenstrasse 6, D-06766 Bitterfeld-Wolfen and ${ }^{4}$ Johann Wolfgang von Goethe-University, Max-von-Laue-Strasse 7, D-60438 Frankfurt am Main, Germany

Email:

Alois Lugstein ${ }^{*}$ - alois.lugstein@tuwien.ac.at

* Corresponding author

\section{Keywords:}

chemical vapour deposition; field-effect transistor; oligosilanes; radiation-induced nanostructures; silicon nanowires;

vapor-liquid-solid mechanism

Beilstein J. Nanotechnol. 2012, 3, 564-569.

doi:10.3762/bjnano.3.65

Received: 30 March 2012

Accepted: 11 May 2012

Published: 31 July 2012

This article is part of the Thematic Series "Radiation-induced nanostructures: Formation processes and applications".

Guest Editor: M. Huth

(C) 2012 Molnar et al; licensee Beilstein-Institut.

License and terms: see end of document.

\begin{abstract}
Perchlorinated polysilanes were synthesized by polymerization of tetrachlorosilane under cold plasma conditions with hydrogen as a reducing agent. Subsequent selective cleavage of the resulting polymer yielded oligochlorosilanes $\operatorname{Si}_{n} \mathrm{Cl}_{2 n+2}(n=2,3)$ from which the octachlorotrisilane $\left(n=3, \mathrm{Cl}_{8} \mathrm{Si}_{3}\right.$, OCTS) was used as a novel precursor for the synthesis of single-crystalline Si nanowires (NW) by the well-established vapor-liquid-solid (VLS) mechanism. By adding doping agents, specifically $\mathrm{BBr}_{3} \mathrm{and}^{\mathrm{PCl}} \mathrm{H}_{3}$, we achieved highly p- and n-type doped Si-NWs by means of atmospheric-pressure chemical vapor deposition (APCVD). These as grown NWs were investigated by means of scanning electron microscopy (SEM) and transmission electron microscopy (TEM), as well as electrical measurements of the NWs integrated in four-terminal and back-gated MOSFET modules. The intrinsic NWs appeared to be highly crystalline, with a preferred growth direction of [111] and a specific resistivity of $\rho=6 \mathrm{k} \Omega \cdot \mathrm{cm}$. The doped NWs appeared to be [112] oriented with a specific resistivity of $\rho=198 \mathrm{~m} \Omega \cdot \mathrm{cm}$ for p-type Si-NWs and $\rho=2.7 \mathrm{~m} \Omega \cdot \mathrm{cm}$ for $\mathrm{n}$-doped Si-NWs, revealing excellent dopant activation.
\end{abstract}

\section{Introduction}

As potential building blocks for nanoelectronics [1,2], biochemical sensors [3,4], light-emitting devices with extremely low power consumption, and solar cells [5], nanotubes [6] and
NWs [7] have drawn a lot of interest during the last two decades. To tune the NWs for their respective applications, their electrical and optical properties, which strongly depend on the 
diameter [8] as well as the crystallographic orientation [9] and defect structure [10] of the NW, must be carefully adjusted. Several synthesis techniques have proven suitable to achieve NWs with tailored properties, namely chemical vapor deposition (CVD) [11], metal-organic CVD [12], molecular-beam epitaxy [13] and laser ablation techniques [14]. In this work we focus on the well-established VLS growth mechanism [15,16], which has shown remarkable potential in the fabrication of straight, crystalline, nanometre-sized wires. During VLS growth a Si precursor is introduced, which is cracked and dissolved into the catalytic liquid phase. Generally Au is used as the catalyst on Si substrates, forming a liquid alloy with a eutectic temperature of $364{ }^{\circ} \mathrm{C}$, which, upon supersaturation, nucleates the growth of a $\mathrm{Si}-\mathrm{NW}$.

In previous work [17] we investigated the crucial importance of substrate preparation in the case of Au-catalysed NWs grown by the VLS mechanism. Removal of silicon oxide shortly before catalyst deposition proved to be decisive for achieving epitaxy and crystallinity. The oxide on top of a Si substrate can also be removed during growth by using $\mathrm{SiCl}_{4}$ as a precursor. Gaseous $\mathrm{HCl}$, a byproduct of $\mathrm{SiCl}_{4}$ decomposition in the presence of $\mathrm{H}_{2}$, etches the native oxide, providing a clean substrate surface for epitaxial NW growth. The same effect can be utilized by intentionally adding $\mathrm{HCl}$ to the growth atmosphere [18]. For such VLS grown NW dopants can be introduced either through particular catalyst particles, such as In [19], Al [20] or Ga [21], which become partly incorporated into the NW during growth and thus work as p-type dopants themselves, or by adding a small amount of dopant intentionally to the Au catalyst particle [22]. Much more common and effective is to add a gaseous dopant, such as $\mathrm{PH}_{3}, \mathrm{~B}_{2} \mathrm{H}_{6}$ or $\mathrm{B}\left(\mathrm{CH}_{3}\right)_{3}$, to the precursor gas feed during growth. Thus, for example, $\mathrm{p}-\mathrm{i}-\mathrm{n}^{+}-$ type doped Si-NW heterostructures with a resistivity of a few $\mathrm{m} \Omega \cdot \mathrm{cm}$ have been achieved [20]. Unfortunately, such in situ doping can negatively affect the actual growth process. $\mathrm{B}_{2} \mathrm{H}_{6}$ for example triggers the formation of an amorphous $\mathrm{Si}$ shell [23], whereas $\mathrm{PH}_{3}$ reduces the growth rate and completely inhibits NW growth at higher $\mathrm{PH}_{3}$ partial pressures [24]. Furthermore, the doping often appears to be radially inhomogeneous and diameter dependent [25]. In this paper we discuss the electric properties of Si-NWs grown with $\mathrm{Si}_{3} \mathrm{Cl}_{8}$ [26] as well as peculiarities of the in situ doped NW synthesis using this precursor in combination with $\mathrm{BBr}_{3}$ or $\mathrm{PCl}_{3}$.

\section{Experimental}

For the synthesis of perchlorinated polysilanes an industrial microwave device (MX 4000, Muegge Electronics GmbH), connected to a rectangular waveguide that leads into a reaction chamber, was used. The reactor itself consisted of a quartz-glass tube, inserted into the microwave cavity, with the axis of the waveguide being perpendicularly aligned to the reaction tube. Prior to use, the reaction apparatus was carefully dried by heating in vacuum. A gaseous mixture of $40 \mathrm{~mL}$ (59.2 g) of $\mathrm{SiCl}_{4}$ and $17 \mathrm{~L}$ of $\mathrm{H}_{2}$ was introduced into the reaction chamber and the pressure was carefully adjusted to 2 mbar. By powering a solid-state Tesla transformer, a glow discharge $(10 \mathrm{~W})$ of about $12 \mathrm{~cm}$ in length was generated. Then, pulsed microwave radiation was used to initiate plasma filling of the whole reaction tube at a length of $8 \mathrm{~cm}$. The microwave pulse duration was set to $1 \mathrm{~ms}$ at $4 \mathrm{~kW}$ followed by a pause of $59 \mathrm{~ms}$, resulting in an average power level of $67 \mathrm{~W}$. The gas mixture was consumed within $200 \mathrm{~min}$ and a white-brown waxy solid (22 g) was deposited on the tube walls. This polymeric material was dissolved in a small amount of $\mathrm{SiCl}_{4}$ and isolated from the reactor. Cryoscopic investigations showed the molecular weight of the polymer to be around $1700 \mathrm{~g} / \mathrm{mol}$, which proves the formation of a perchlorinated polysilane $\left(\mathrm{SiCl}_{2}\right)_{n}$ and/or of $\mathrm{Si}_{n} \mathrm{Cl}_{2 n+2}$, with an average chain length of about $n=17$ for $\left(\mathrm{SiCl}_{2}\right)_{n}$ or $n=16$ for $\mathrm{Si}_{n} \mathrm{Cl}_{2 n+2}$. Moreover the molar ratio of $\mathrm{Si} / \mathrm{Cl}$ was found to be 1:2 by titration after Mohr [27]. Similar to the process described in the literature [28], $50 \mathrm{~g}$ of the perchlorinated polysilane were dissolved in $500 \mathrm{~mL}$ of $\mathrm{SiCl}_{4}$ and placed in a $1 \mathrm{~L}$ flask equipped with a reflux condenser, a stirrer and a gas inlet. The reflux condenser was connected with a cooling trap $\left(-20{ }^{\circ} \mathrm{C}\right)$. Dry chlorine gas was slowly passed through the reaction solution at the reflux temperature of $\mathrm{SiCl}_{4}$ $\left(\sim 57^{\circ} \mathrm{C}\right)$. The reflux temperature was slowly raised but kept below the boiling point of $\mathrm{Si}_{2} \mathrm{Cl}_{6}$, whereupon most of the $\mathrm{SiCl}_{4}$ was distilled off. After $10 \mathrm{~h}$ the slightly yellow solution was distilled at normal pressure to separate $\mathrm{SiCl}_{4}, \mathrm{Si}_{2} \mathrm{Cl}_{6}\left(T_{\mathrm{B}}=\right.$ $\left.145{ }^{\circ} \mathrm{C} / 760 \mathrm{mmHg}, 25 \mathrm{~g}\right)$, and $\mathrm{Si}_{3} \mathrm{Cl}_{8}\left(T_{\mathrm{B}}=215^{\circ} \mathrm{C} / 760 \mathrm{mmHg}\right.$, $16 \mathrm{~g}$ ). Higher oligosilanes remained in the distillation residue and were not isolated. For characterization of the precursor compounds, $\mathrm{Si}_{2} \mathrm{Cl}_{6}$ and $\mathrm{Si}_{3} \mathrm{Cl}_{8}$ were identified by their characteristic ${ }^{29} \mathrm{Si} \mathrm{NMR}$ chemical shifts $\left(\mathrm{Si}_{2} \mathrm{Cl}_{6}, \delta=-6.4 \mathrm{ppm}\right.$; $\left.\mathrm{Si}_{3} \mathrm{Cl}_{8}, \delta=-3.7\left(-\mathrm{SiCl}_{3}\right),-7.4 \mathrm{ppm}\left(-\mathrm{SiCl}_{2}-\right)\right)[29,30]$ and by GC-MS measurements. Trace analysis was performed by ICP-MS measurements. For the preparation of the doped samples, $\mathrm{BBr}_{3}$ and $\mathrm{PCl}_{3}$ were added to the oligosilanes in very small quantities (100 ppm). After distillation the doped oligosilanes were directly used for NW growth in an APCVD system.

The main components of the APCVD growth chamber are a horizontal tube furnace with three individually controlled heating zones, a quartz tube connected to a gas feed, and a pumping unit. To supply the furnace with gaseous OCTS precursor a saturator was utilized with $\mathrm{He}$ as the feed gas. A more detailed description of the growth apparatus is given in [30]. As substrates, pieces of Si (111) were cleaned with acetone, rinsed with propan-2-ol and blown dry with $\mathrm{N}_{2}$. The 
native oxide was removed by buffered hydrofluoric acid (BHF; $\mathrm{HF} / \mathrm{NH}_{4} \mathrm{~F}$ 7:1) resulting in a hydrogen-terminated Si surface. Au colloids $(80 \mathrm{~nm})$ in propan-2-ol were then dropped onto the substrate and after evaporation of the solvent and an additional dip in BHF, the samples were immediately introduced into the APCVD system. The reactor was evacuated and purged with $\mathrm{He}$, three times, to remove any traces of air. Thereafter the temperature was ramped up with the samples still outside of the heated zone, under a flow of $100 \mathrm{sccm}$ of He. When the furnace reached the final growth temperature the sample holder was transferred into the growth region with the aid of a magnetic specimen-transport system, enabling accurate and fast placement of the samples at desired temperatures without breaking the vacuum. It turned out that annealing of the samples for $30 \mathrm{~min}$ at $800{ }^{\circ} \mathrm{C}$ prior to growth improved epitaxy considerably. After this pre-annealing, OCTS was introduced into the growth atmosphere with a partial pressure of $\sim 0.03$ mbar by routing the He through the saturator. Taking into account the temperature gradient of the furnace, process temperatures from 900 to $400{ }^{\circ} \mathrm{C}$ in steps of $100{ }^{\circ} \mathrm{C}$ were investigated simultaneously within the same growth sequence, which gave the most direct and reliable information about the influence of the growth temperature [30]. After the standard growth duration of $60 \mathrm{~min}$, the sample holder was pulled out of the heating zone with the magnetic specimen-transport system, enabling a very fast cool down of the samples, which still remained in the growth atmosphere. Finally, the precursor gas flow was stopped, and the quartz tube was purged with He for a further 5 min before the sample was removed from the APCVD system.

For contacting the NWs, $200 \times 200 \mu \mathrm{m}^{2} \mathrm{Au}$ pads were structured on a highly doped $\mathrm{Si}$ (100) wafer, capped with $80 \mathrm{~nm}$ $\mathrm{Al}_{2} \mathrm{O}_{3}$, by photolithography and lift-off techniques. VLS-grown $\mathrm{Si}-\mathrm{NWs}$ were then removed from their growth substrates by ultrasonication in propan-2-ol. Subsequently the NWs were randomly distributed by dropping the suspension onto the above mentioned $\mathrm{Si}(100)$ wafer with prepatterned Au pads. Finally the NWs were connected to the prepatterned Au pads by electron beam lithography, Ni sputter deposition and lift-off techniques.

\section{Results and Discussion}

Single-crystalline and epitaxial Si-NWs were grown by using OCTS as a precursor and $\mathrm{Au}$ colloids at a growth temperature of $700{ }^{\circ} \mathrm{C}$, with a pre-annealing of the samples at $800{ }^{\circ} \mathrm{C}$ for 30 min. The thus synthesized NWs, shown in Figure 1a, were 4 to $10 \mu \mathrm{m}$ long and 80 to $100 \mathrm{~nm}$ thick.

Based on such an optimized NW synthesis procedure, we added $\mathrm{BBr}_{3}$ to the OCTS precursor expecting the formation of $\mathrm{p}$-type doped Si-NWs. However, the addition of $\mathrm{BBr}_{3}$ strongly affects the growth behaviour. Notably, effective growth of B-doped Si-NWs with OCTS and $\mathrm{BBr}_{3}$ requires a reduction of the growth temperature and the addition of $\mathrm{H}_{2}$. Remarkably, the addition of $\mathrm{H}_{2}$ during the growth of intrinsic NWs causes significant etching under the given experimental conditions [30]. However, adding $10 \mathrm{sccm}$ of $\mathrm{H}_{2}$ for the synthesis of p-type doped NWs yielded epitaxial, 10 to $20 \mu \mathrm{m}$ long and 80 to $150 \mathrm{~nm}$ thick Si-NWs at a growth temperature of $600{ }^{\circ} \mathrm{C}$ (Figure 1b). NWs were observed in large quantity down to temperatures of $400{ }^{\circ} \mathrm{C}$, but epitaxy deteriorated with decreasing temperature. To achieve n-type $\mathrm{Si}-\mathrm{NWs}, \mathrm{PCl}_{3}$ was added to OCTS. Again effective NW growth required the addition of $\mathrm{H}_{2}$ to the growth atmosphere and a higher growth temperature of at least $800^{\circ} \mathrm{C}$. Furthermore, to achieve epitaxial NW growth, the colloids were replaced by a $2 \mathrm{~nm}$ thick sputterdeposited Au layer. Epitaxial NWs about $60 \mathrm{~nm}$ to $150 \mathrm{~nm}$ in diameter and up to $30 \mu \mathrm{m}$ long are shown in Figure 1c.

Summarizing the synthesis results, one has to note that even small amounts (ppm) of the doping agent change the growth

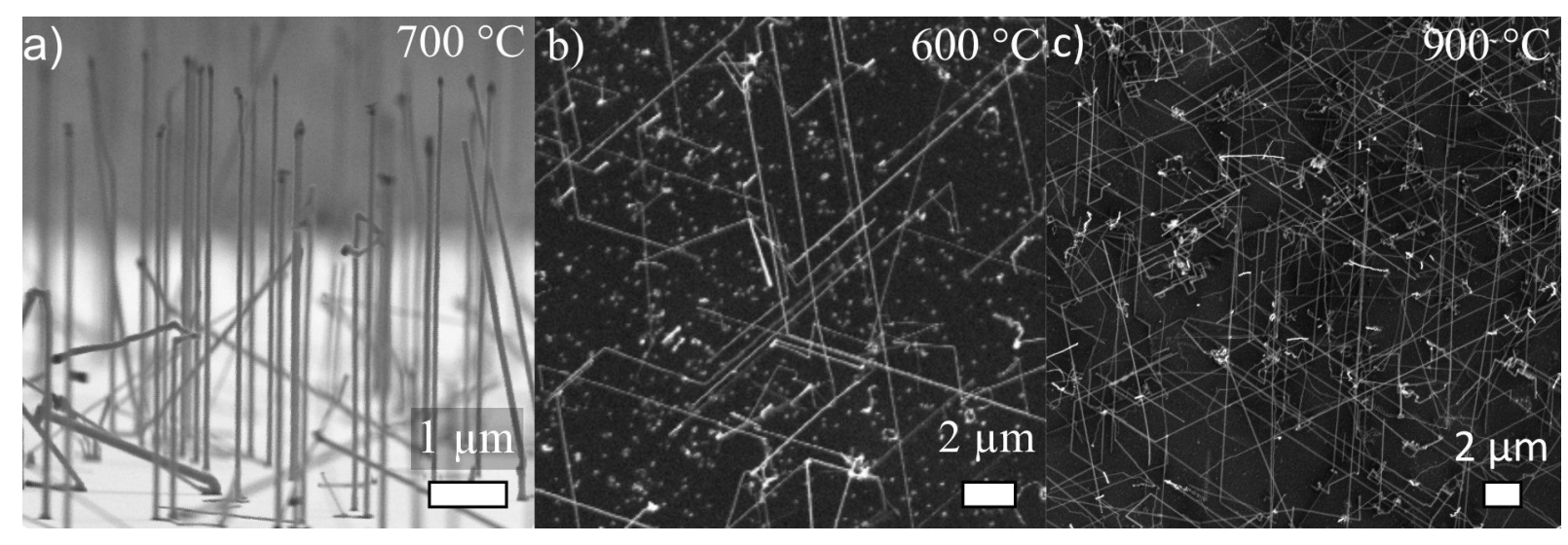

Figure 1: (a) tilted-view SEM image of Au-catalysed NWs grown at $700{ }^{\circ} \mathrm{C}$ with OCTS, (b) top-view SEM image of boron-doped Si-NWs grown at $600^{\circ} \mathrm{C}$, (c) SEM image of phosphorus-doped NWs grown at $900^{\circ} \mathrm{C}$. 
behaviour considerably. For pure OCTS we achieved effective $\mathrm{Si}-\mathrm{NWs}$ growth in the temperature regime from 600 to $900{ }^{\circ} \mathrm{C}$ without any $\mathrm{H}_{2}$, though with varying quality. With the addition of $\mathrm{BBr}_{3}$, NWs growth was restricted to the temperature regime between 400 and $600{ }^{\circ} \mathrm{C}$, although this required the addition of $\mathrm{H}_{2}$ to the growth atmosphere. Briand et al. [31] also reported lower growth temperatures when adding $\mathrm{B}_{2} \mathrm{H}_{6}$ to $\mathrm{SiH}_{4}$, as boron promotes the decomposition of the precursor and therefore increases the growth rate. With $\mathrm{PCl}_{3}$ as the dopant, at least $800{ }^{\circ} \mathrm{C}, 20 \mathrm{sccm} \mathrm{H}_{2}$, and a $2 \mathrm{~nm}$ layer of Au were needed to produce epitaxial NWs in considerable quantity. For a more detailed view of the morphology of the intrinsic and doped Si-NWs we performed HRTEM investigations. The TEM image in Figure 2a shows a slightly tapered, intrinsic Si-NW with a catalytic particle atop. The HRTEM micrograph of the crystalline core in Figure $2 \mathrm{~b}$ shows clearly the $\mathrm{Si}(111)$ atomic planes (separation $3.14 \AA$ ) perpendicular to the NW axis. The reciprocal lattice peaks in the diffraction pattern (inset in Figure 2b) prove that the growth axis is [111], and previous work on Si-NWs grown with $\mathrm{SiH}_{4}$ revealed, vertical $\{112\}$ facets [32]. The NWs are usually free of dislocations and stacking faults and are covered by a very thin oxide layer.

As already mentioned above, the addition of $\mathrm{B}_{2} \mathrm{H}_{6}$ requires the modification of growth parameters, such as temperature and feed-gas composition, to achieve effective NW growth. Moreover the addition of the dopant species, and thus the expected insertion of B into the lattice of the Si-NW, also influences the morphology and crystal orientation. Nevertheless, they have comparable diameters to those of the intrinsic NWs grown with pure OCTS. The growth orientation of the p-type doped NWs appears to be [112], as shown in the HRTEM image and the respective diffraction pattern (Figure 2c,d). Stacking faults run along the entire NW from the base to the top, and the crystalline core is enwrapped by an amorphous shell. A similar amorphous shell was also observed by Lauhon et al. [33] on addition of $\mathrm{B}_{2} \mathrm{H}_{6}$ to the growth atmosphere with the $\mathrm{SiH}_{4}$ precursor. The images in Figure 2e and Figure $2 \mathrm{f}$ show that also $\mathrm{PCl}_{3}$ affects NW growth by changing the growth direction. Such epitaxial NWs grow preferentially along the [112] direction, like their B-doped counterparts. The NWs themselves are rod-like, exhibit good crystallinity, and feature no observable defects or stacking faults.

To test the activation of the dopants in the NWs, electrical characterization was performed with back-gated Schottky-barrier NW-FETs and four-point measurement modules. The results of the four-point measurements and the back-gated measurements are illustrated in Figure 3. The four-point measurements of nominally intrinsic NWs grown with pure OCTS revealed a resistivity of about $5.9 \mathrm{k} \Omega \cdot \mathrm{cm}$. This is in accordance with the

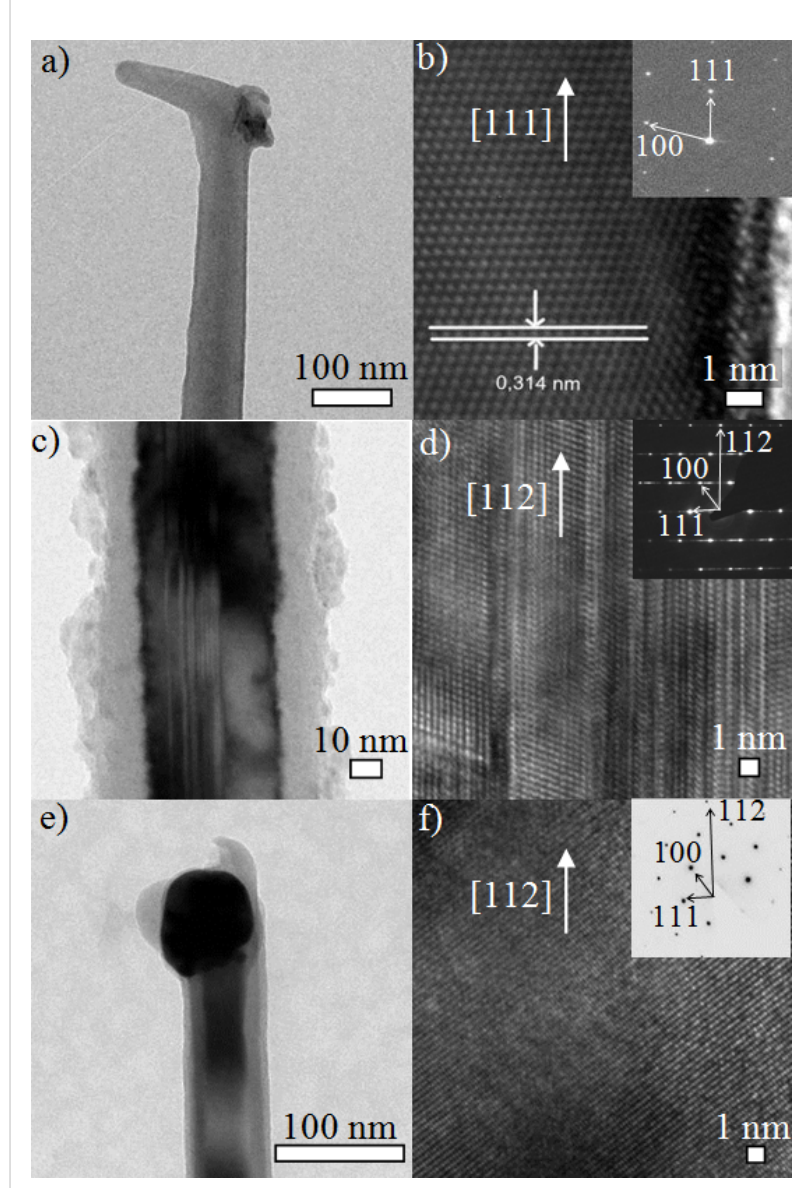

Figure 2: TEM images (a), (c) and (e) show impressions of intrinsic, B-doped and P-doped NWs respectively. Analogously (b), (d) and (f) represent the respective HRTEM images with diffraction images in the inset.

results of Heath et al. [34], who reported a specific resistivity of intrinsic NWs, grown with $\mathrm{SiH}_{4}$ as a precursor, of about $1 \mathrm{k} \Omega \cdot \mathrm{cm}$. Back-gated measurements revealed an unintentionally p-type doping leading to a threshold voltage of $-4.5 \mathrm{~V}$ (Figure 3 inset). Such p-type behaviour is observed for most intrinsic VLS-grown Si-NWs and can be attributed to hole accumulation at the surface due to trapped negative surface charge, although contributions from impurities such as $\mathrm{Au}$ and O cannot be excluded completely [35].

For the as grown intentionally p-doped NWs, we determined a resistivity of about $862 \Omega \cdot \mathrm{cm}$. This rather high resistivity arose from the immense amorphous shell (see Figure 2c) wrapped around a highly crystalline core. Thus, in the case of the intentionally B-doped NWs, an annealing step at $470{ }^{\circ} \mathrm{C}$ for $2 \mathrm{~min}$ was required to achieve reliable contacts. Subsequent measurements revealed a specific resistivity of $198 \mathrm{~m} \Omega \cdot \mathrm{cm}$ (Figure 3), which corresponds to an active dopant concentration of $10^{17} \mathrm{~cm}^{-3}$ in bulk Si. A similar behaviour was also reported by 


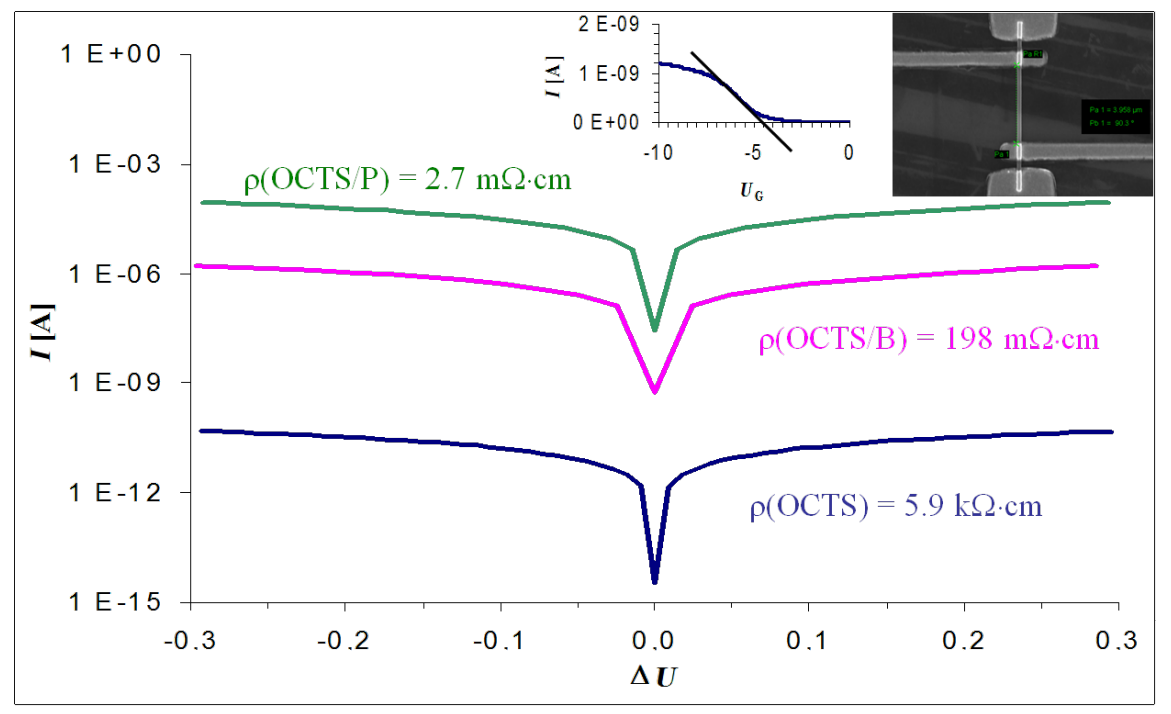

Figure 3: Semilogarithmic I/V plot of intrinsic, p- and n-type NWs. The calculated specific resistivity values are shown next to the respective curves. The transfer characteristic of the intrinsic NW integrated into a back-gated Schottky-barrier NW-FET and a SEM image of a four-point setup is shown in the inset.

Lauhon et al. [35]. The p-type doped NWs showed a high resistivity in the $\mathrm{k} \Omega \cdot \mathrm{cm}$ regime, which can be reduced upon annealing to a few $\mathrm{m} \Omega \cdot \mathrm{cm}$ as a result of complete crystallisation. Adding $\mathrm{PCl}_{3}$ to the growth atmosphere results in n-type Si-NWs with a resistivity of $2.7 \mathrm{~m} \Omega \cdot \mathrm{cm}$, corresponding to an active $P$ concentration of $3 \times 10^{19} \mathrm{~cm}^{-3}$ in bulk Si. Remarkably this is more than six orders of magnitude lower than the resistivity of the intrinsic NWs in this work. Due to the high doping level we observed no channel modulation in response to the gate voltage for the doped NWs integrated in back-gated FETs.

\section{Conclusion}

In conclusion, OCTS appeared to be a favourable precursor for VLS synthesis of intrinsic as well as in situ doped NWs. However, the addition of $\mathrm{BBr}_{3}$ and $\mathrm{PCl}_{3}$ as doping agents requires a careful tuning of the growth parameters. NWs synthesized with pure OCTS exhibit a growth orientation of [111], while the doped NWs appear to be predominantly [112] oriented. Finally the electrical characterisation revealed a resistivity of $5.9 \mathrm{k} \Omega \cdot \mathrm{cm}$ for intrinsic Si-NWs, which appeared to be unintentionally p-type doped and $198 \mathrm{~m} \Omega \cdot \mathrm{cm}$ and $2.7 \mathrm{~m} \Omega \cdot \mathrm{cm}$ for the B- and P-doped NWs, respectively. This proves that the electronic properties of Si-NWs grown with OCTS as Si precursor can be tuned according to the desired applications. Also the growth orientation can be controlled, which may prove useful for device integration. Therefore OCTS-grown NWs represent promising new alternatives in the upcoming fields of nanoelectronics, optics, thermoelectronics and sensor devices [36].

\section{References}

1. Duan, X.; Huang, Y.; Lieber, C. M. Nano Lett. 2002, 2, 487-490. doi:10.1021/nl025532n

2. Javey, A.; Nam, S.; Friedman, R. S.; Yan, H.; Lieber, C. M. Nano Lett. 2007, 7, 773-777. doi:10.1021/n1063056l

3. Cui, Y.; Lieber, C. M. Science 2001, 291, 851-853. doi:10.1126/science.291.5505.851

4. Zheng, G.; Patolsky, F.; Cui, Y.; Wang, W. U.; Lieber, C. M. Nat. Biotechnol. 2005, 23, 1294-1301. doi:10.1038/nbt1138

5. Pettersson, H.; Trägårdh, J.; Persson, A. I.; Landin, L.; Hessman, D.; Samuelson, L. Nano Lett. 2006, 6, 229-232. doi:10.1021/nl052170l

6. Martel, R.; Derycke, V.; Lavoie, C.; Appenzeller, J.; Chan, K. K.; Tersoff, J.; Avouris, P. Phys. Rev. Lett. 2001, 87, 256805. doi:10.1103/PhysRevLett.87.256805

7. Duan, X.; Huang, Y.; Cui, Y.; Wang, J.; Lieber, C. M. Nature 2001, 409, 66-69. doi:10.1038/35051047

8. Brus, L. J. Phys. Chem. 1994, 98, 3575-3581. doi:10.1021/j100065a007

9. Yorikawa, H.; Uchida, H.; Muramatsu, S. J. Appl. Phys. 1996, 79, 3619. doi:10.1063/1.361416

10. Mozos, J. L.; Machado, E.; Hernandez, E.; Ordejon, P. Int. J. Nanotechnol. 2005, 2, 114-128.

11. Wagner, R. S.; Ellis, W. C. Appl. Phys. Lett. 1964, 4, 89. doi:10.1063/1.1753975

12. Arakawa, Y. Solid-State Electron. 1994, 37, 523-528. doi:10.1016/0038-1101(94)90238-0

13. Martelli, F.; Piccin, M.; Bais, G.; Jabeen, F.; Ambrosini, S.; Rubini, S.; Franciosi, A. Nanotechnology 2007, 18, 125603. doi:10.1088/0957-4484/18/12/125603

14. Wang, N.; Tang, Y. H.; Zhang, Y. F.; Lee, C. S.; Lee, S. T. Phys. Rev. B 1998, 58, R16024-R16026. doi:10.1103/PhysRevB.58.R16024

15. Levitt, A. P., Ed. Whisker Technology; Wiley-Interscience: New York, 1970. 
16. Givargizov, E. I. J. Cryst. Growth 1975, 31, 20-30 doi:10.1016/0022-0248(75)90105-0

17. Lugstein, A.; Hyun, Y. J.; Steinmair, M.; Dielacher, B.; Hauer, G.; Bertagnolli, E. Nanotechnology 2008, 19, 485606. doi:10.1088/0957-4484/19/48/485606

18. Sharma, S.; Kamins, T. I.; Stanley Williams, R. J. Cryst. Growth 2004, 267, 613-618. doi:10.1016/j.jcrysgro.2004.04.042

19. lacopi, F.; Vereecken, P. M.; Schaekers, M.; Caymax, M.; Moelans, N.; Blanpain, B.; Richard, O.; Detavernier, C.; Griffiths, H. Nanotechnology 2007, 18, 505307. doi:10.1088/0957-4484/18/50/505307

20. Björk, M. T.; Knoch, J.; Schmidt, H.; Riel, H.; Riess, W. Appl. Phys. Lett. 2008, 92, 193504. doi:10.1063/1.2928227

21. Sharma, S.; Sunkara, M. K. Nanotechnology 2004, 15, 130. doi:10.1088/0957-4484/15/1/025

22. Schmidt, V.; Riel, H.; Senz, S.; Karg, S.; Riess, W.; Gösele, U. Small 2006, 2, 85-88. doi:10.1002/smll.200500181

23. Lew, K.-K.; Pan, L.; Bogart, T. E.; Dilts, S. M.; Dickey, E. C.; Redwing, J. M.; Wang, Y.; Cabassi, M.; Mayer, T. S.; Novak, S. W. Appl. Phys. Lett. 2004, 85, 3101. doi:10.1063/1.1792800

24. Schmid, H.; Björk, M. T.; Knoch, J.; Karg, S.; Riel, H.; Riess, W. Nano Lett. 2009, 9, 173-177. doi:10.1021/nl802739v

25. Xie, P.; Hu, Y.; Fang, Y.; Huang, J.; Lieber, C. M. Proc. Natl. Acad. Sci. U. S. A. 2009, 106, 15254-15258. doi:10.1073/pnas.0906943106

26. Molnar, W.; Lugstein, A.; Pongratz, P.; Auner, N.; Bauch, C.; Bertagnolli, E. Nano Lett. 2010, 10, 3957-3961. doi:10.1021/nl101744q

27. Jander, G.; Blasius, E. Einführung in das anorganisch-chemische Praktikum; S. Hirtzel Verlag: Stuttgart, 1995.

28. Schmeisser, M.; Voss, P. Z. Anorg. Allg. Chem. 1964, 334, 50-56. doi:10.1002/zaac.19643340108

29. Sharp, K. G.; Sutor, P. A.; Williams, E. A.; Cargioli, J. D.; Farrar, T. C.; Ishibitsu, K. J. Am. Chem. Soc. 1976, 98, 1977-1979. doi:10.1021/ja00423a062

30. Marsmann, H. C.; Raml, W.; Hengge, E. Z. Naturforsch. 1980, 35b, 35-37.

31. Briand, D.; Sarret, M.; Kis-Sion, K.; Mohammed-Brahim, T.; Duverneuil, P. Semicond. Sci. Technol. 1999, 14, 173-180. doi:10.1088/0268-1242/14/2/012

32. Lugstein, A.; Andrews, A. M.; Steinmair, M.; Hyun, Y.-J.; Bertagnolli, E.; Weil, M.; Pongratz, P.; Schramböck, M.; Roch, T.; Strasser, G. Nanotechnology 2007, 18, 355306. doi:10.1088/0957-4484/18/35/355306

33. Lauhon, L. J.; Gudiksen, M. S.; Wang, D.; Lieber, C. M. Nature 2002, 420, 57-61. doi:10.1038/nature01141

34. Yu, J.-Y.; Chung, S.-W.; Heath, J. R. J. Phys. Chem. B 2000, 104, 11864-11870. doi:10.1021/jp002595q

35. Zhang, S.; Hemesath, E. R.; Perea, D. E.; Wijaya, E.; Lensch-Falk, J. L.; Lauhon, L. J. Nano Lett. 2009, 9, 3268-3274. doi:10.1021/nl901548u

36. Sarkar, J.; Khan, G. G.; Basumallick, A. Bull. Mater. Sci. 2007, 30, 271-290. doi:10.1007/s12034-007-0047-0

\section{License and Terms}

This is an Open Access article under the terms of the Creative Commons Attribution License

(http://creativecommons.org/licenses/by/2.0), which permits unrestricted use, distribution, and reproduction in any medium, provided the original work is properly cited.

The license is subject to the Beilstein Journal of Nanotechnology terms and conditions: (http://www.beilstein-journals.org/bjnano)

The definitive version of this article is the electronic one which can be found at:

doi:10.3762/bjnano.3.65 